Alcohol Clin Exp Res. 2013 May ; 37(5): 717-719. doi:10.1111/acer.12083.

\title{
The Role of Race/Ethnicity in Alcohol-attributable Injury in the United States
}

\author{
Katherine M. Keyes ${ }^{\star}$, Xianfang C. Liu, and Magdalena Cerda \\ Department of Epidemiology, Columbia University, New York, New York (Katherine M. Keyes, \\ Xianfang C. Liu, Magdalena Cerda); and Department of Psychiatry, Division of Clinical \\ Phenomenology, New York State Psychiatric Institute, New York, New York (Katherine M. Keyes)
}

\begin{abstract}
A substantial proportion of injuries worldwide are attributable to alcohol consumption, and US estimates indicate that the drinking patterns of racial/ethnic groups vary considerably. The authors reviewed evidence from 19 publications regarding racial/ethnic differences in overall alcoholattributable injury as well as percent blood alcohol content positivity for injury deaths in the United States. They found that Native Americans evidence higher rates of alcohol-attributable motor vehicle crash fatality, suicide, and falls compared with other racial/ethnic groups; conversely, Asians evidence lower rates of alcohol-attributable injury than other racial/ethnic groups. The rate of alcohol positivity and intoxication among Hispanics is disproportionately high relative to estimates of alcohol use. Black subgroups also evidence higher rates of alcohol positivity than would be expected given estimates of alcohol use, including for alcohol positivity among drivers of fatally injured black children and homicide. These findings highlight the continued need for public health focus on Native American populations with respect to alcohol consumption and injury. Further, the disparity in alcohol-attributable injury mortality among black and Hispanic groups relative to their reported rates of alcohol consumption is an overlooked area of research. The authors review potential social determinants of racial/ethnic disparities in alcoholattributable injuries and identify directions for further research on these patterns.
\end{abstract}

\section{Keywords}

accidents; alcohol drinking; alcoholic intoxication; homicide; minority health; motor vehicles; suicide; wounds and injuries

\section{INTRODUCTION}

\begin{abstract}
Harmful patterns of alcohol drinking account for approximately $4 \%$ of all deaths of men and $1.5 \%$ of women in the United States (1). Worldwide, alcohol is a contributing factor in an estimated $3.8 \%$ of deaths; $4.6 \%$ of global disability-adjusted life-years lost are attributed to alcohol $(2,3)$. Deaths due to intentional and unintentional injury are strongly linked to
\end{abstract}

For permissions, please e-mail: journals.permissions@oup.com

*Correspondence to Dr. Katherine M. Keyes, Department of Epidemiology, Columbia University, 722 West 168th Street, 7th Floor, New York, NY 10032 kmk2104@ columbia.edu.

Conflict of interest: none declared. 
alcohol consumption, especially among young people $(4,5)$, with an estimated $23 \%$ of injurious death in the United States attributable at least in part to alcohol consumption (3). While public health prevention and intervention efforts have been successful in reducing the number of injurious deaths attributable to alcohol in the last 20 years (6), alcoholattributable injury remains a major public health problem in the United States and worldwide (7).

Injury is a heterogeneous category describing deaths with likely multiple etiologies, including but not limited to intentional injury involving homicide or suicide to unintentional injury involving motor vehicle crash, poisoning, and drowning (8). Despite the diversity of these outcomes, some common demographic trends emerge when examining injury deaths due to alcohol use. In general, demographic groups with higher rates of alcohol consumption and alcohol use disorder have higher rates of alcohol-attributable injury; for example, men and young adults, compared with women and older adults, respectively, are more likely to die from an alcohol attributable injury (9). Given the pervasive health disparities by racial/ ethnic status in the United States, examining the distribution of alcohol-attributable injuries by race/ethnicity is particularly important.

Preliminary evidence suggests a potentially complex distribution of alcohol-attributable injury outcomes by race/ethnicity, given that health outcomes by race/ethnicity more generally present paradoxical associations with respect to alcohol. All major epidemiologic surveys in the United States report that blacks and Hispanics have lower rates of lifetime and past-year alcohol consumption, binge drinking, and alcohol use disorders compared with non-Hispanic whites. Shown in Table 1 are data from a national survey that exemplifies this research, indicating that blacks and Hispanics have a lower prevalence of lifetime alcohol use, alcohol use disorders, binge drinking, and frequent binge drinking (10).

These findings may lead us to expect a lower risk of alcohol-related health problems among blacks and Hispanics, yet the opposite is the case: for example, rates of alcohol-attributable cancers such as those of the esophagus and larynx are higher among non-Hispanic black men compared with non-Hispanic white men $(11,12)$. While evidence indicates that blacks and Hispanics have a greater persistence of alcohol dependence compared with nonHispanic whites (13), higher rates of some problems associated with alcohol among drinkers $(13,14)$, and potentially higher levels of drinking among those in older age groups (15), blacks and Hispanics remain the only demographic group for which rates of overall alcohol use do not match rates of alcohol-attributable injury. These patterns suggest that a complex phenomenon may also underlie racial/ethnic distribution of alcohol-attributable injuries. Examining racial/ethnic differences in injury is important to identify groups at higher risk, necessary for public health intervention and planning efforts.

No previous review has, to our knowledge, synthesized the evidence for racial/ethnic differences across intentional and unintentional injury outcomes. To provide a frame for understanding the patterning of racial/ethnic differences in alcohol-attributable injury, we examine these rates compared with national estimates of alcohol consumption and alcohol disorder indicators, evaluating whether patterning of injury corresponds to what would be expected given racial/ethnic differences in alcohol consumption and disorder. We review 
evidence for racial/ethnic differences in overall rates of alcohol-attributable injury as well as percent alcohol positivity among those with injurious deaths from motor vehicle crash (resulting in driver, occupant, or pedestrian injury), suicide, homicide, and other unintentional injury (e.g., drowning, poisoning, and falls). These injuries represent the most common injury deaths in the United States.

\section{METHODS}

We collected peer-reviewed as well as Centers for Disease Control and Prevention surveillance reports on all alcohol-attributable injury outcomes using PubMed and Medline databases as well as searches of Centers for Disease Control and Prevention Morbidity and Mortality Weekly Reports. We used the keywords "alcohol-attributable" and/or "alcohol" with the following conjoiners: "homicide," "suicide," "motor vehicle crash," "motor vehicle fatality," "pedestrian fatality," "drowning," "poisoning," and "hip fracture." This initial search netted 163 articles using "alcohol-attributable" as a conjoiner. Initially, 6,019 abstracts were identified using the less sensitive "alcohol" as a conjoiner; thus, other conjoiners were added as necessary (e.g., "fatal," "mortality," or "injury") to restrict articles to a reasonable number for review. We then reviewed abstracts and full articles when necessary to select publications in which 1) data on alcohol involvement of the affected population were collected (either blood alcohol content or alcohol-attributable proportion of injury), and 2) racial/ethnic differences were presented. Lack of information on racial/ethnic differences was the primary driver of abstract exclusion. Publications from only 1970 to 2010 were considered to focus the review on the most up-to-date information. Publications were considered related to injury if outcomes were listed among the International Classification of Diseases, Ninth Revision or International Statistical Classification of Diseases and Related Health Problems, Tenth Revision codes given in Table 2.

On the basis of these criteria, we selected 14 papers for the review. We also used reference lists of search-identified papers for other relevant literature, which netted an additional 5 papers. A total of 19 papers met our search criteria and are included in the present review.

\section{Racial/ethnic status}

Assessing and recording race and ethnicity are problematic for a number of reasons. These categories are in constant flux, and no consensus regarding the concept of race has been formed in scientific research. Some researchers question the value of assessing race at all, given the ambiguities and lack of clear boundaries among groups and the problematic history of scientific research on racial/ethnic minorities (16). However, assessment of racial/ ethnic variation in health outcomes is necessary to document health disparities in the population, health status, and access to health resources. Racial/ethnic categories varied across the studies we reviewed on a number of dimensions, including number of groups compared, racial/ethnic composition of each category, label given to each racial/ethnic category, and source of racial/ethnic data. For the present review, we retained the exact wording of racial/ethnic group used by the study authors, recognizing that these categories are not fixed biologic traits but rather are refracted through the lens of social influence. 


\section{Types of data reported}

In general, 2 types of racial/ethnic differences are reported: 1) overall racial/ethnic differences in population rates of alcohol-attributable injury; and 2) among individuals who suffered a particular injury, the percentage who were alcohol positive and/or met criteria for legal intoxication (typically defined as blood alcohol content $=0.1 \mathrm{~g} / \mathrm{dL}$ ). Each measure provides unique and important information. Overall alcohol-attributable injury rates provide data on the public health burden of injury by race/ethnicity, but the competing causes of injury cannot be disentangled (i.e., racial/ethnic differences in overall alcohol-attributable injury may be due to overall differences in the rate of that injury outcome by race/ethnicity irrespective of alcohol involvement). Percent blood alcohol content positivity among those with an injury controls for the competing causes of the outcome and provides data on the relation between race/ethnicity and intoxication. Overall rates of alcohol-attributable injury are generally calculated by using Alcohol-Related Disease Impact (ARDI) software, which was designed to estimate the proportion of alcohol-attributable injury (and other) fatalities (17) using estimated attributable fractions based on empirical studies.

\section{RESULTS}

\section{Motor vehicle crash morbidity and mortality: drivers, child occupants, and pedestrian road users}

Studies assessing racial/ethnic differences in motor vehicle crash are shown in Table 3 . The largest body of literature on racial/ethnic differences in injury concerns motor vehicle crash morbidity and mortality, and data are largely derived from the Fatality Analysis Reporting System (FARS) of the National Highway Traffic Safety Administration, both combining data across US states to give national estimates (18-21) and provide state-specific estimates (22-25).

\section{Overall alcohol-attributable injury rate}

Native American subgroups: All studies that have examined Native-American racial/ethnic groups (or have included "other" race/ethnicity in which the predominant group is Native Americans) have found that Native Americans have the highest rate of alcohol-attributable crash fatality $(22,24,26)$ as well as pedestrian fatality $(23)$.

Black and Hispanic subgroups: When black and Hispanic populations compared with nonHispanic whites are considered, data are less consistent. Some studies show that nonwhites (27), and more specifically Hispanics (12), have a higher alcohol-attributable motor vehicle crash fatality rate compared with whites ( 1.1 vs. 0.5 per 100 licenses among males according to Popkin and Council (27) and 9.2 vs. 8.2 per 100,000 per Sutocky et al. (12)). Rates of alcohol-related pedestrian death in Arizona are substantially higher in Hispanic and black populations compared with whites (23). However, national data from FARS suggest that the overall rate of alcohol-related motor vehicle crash for blacks is less than half that for whites and is also decreased for Hispanics (24). Hispanics in California have less than half the rate of alcohol-attributable motor vehicle crash compared with non-Hispanic whites (26). Further, examining rates by subgroup variation has yielded important insights. Nonwhites in 
Florida had higher rates of alcohol-attributable motor vehicle crash for only those aged 55 years or older (28), suggesting important age-related variation in racial/ethnic differences.

Asian subgroups: One study examined Asians as a specific subgroup and found that they evidence the lowest rate of alcohol-attributable injury compared with all other racial/ethnic groups (26).

\section{Percent blood alcohol content positivity}

Native American subgroups: Similar to studies reporting overall rates of motor vehicle crash fatality, those studies that included data on Native-American race/ethnicity have shown that the proportion of motor vehicle crash fatality victims who were alcohol positive was highest among Native Americans $(18,20)$.

Hispanic subgroups: Data on Hispanic subgroups suggest a pattern of increasing risk compared with non-Hispanic whites as well $(21,25)$. Note, however, that Voas et al. (20) documented substantial within-Hispanic-group variation in percent alcohol positivity among drivers fatally injured in a motor vehicle crash.

Black subgroups: Data on percent blood alcohol content positivity among black subgroups compared with whites suggest similar or higher percentages of blood alcohol content positivity. National data from FARS indicate that non-Hispanic blacks have a similar percentage of blood alcohol content positivity compared with non-Hispanic whites (45.2\% vs. 44.2\%, respectively, from 1990 to 1994 (20) and 51\% vs. 47\%, respectively, in 1995) (21). Regarding drivers of fatally injured children, however, black drivers are more likely to be blood alcohol content positive than white drivers are $(18,19)$.

Asian subgroups: Studies that have examined Asian race/ethnicity find that individuals in this group, compared with other racial/ethnic groups, evidence low rates of alcohol positivity following motor vehicle crash $(18,20)$.

\section{Intentional injury: suicide}

Studies of racial/ethnic differences in intentional injury are shown in Table 4.

\section{Overall alcohol-attributable injury rate}

Native American subgroups: Native American race/ethnicity was not specifically identified in either of the 2 studies documenting suicide; instead, it was combined into a global "other" category. In the study by Sutocky et al. (12), this group comprised primarily Native Americans and Asians. Stahre and Simon (26) disaggregated rates between Asians and the "other" racial/ethnic group (predominately comprising Native Americans) and found that the "other" group had the highest rate of alcohol-attributable suicide (30.9 per 100,000).

Black and Hispanic subgroups: Both studies found that blacks and Hispanics have lower rates of alcohol-attributable suicide compared with non-Hispanic whites $(12,26)$. 
Asian subgroups: Studies that have examined Asian race/ethnicity find that individuals in this group evidence low rates of alcohol-attributable suicide compared with other racial/ ethnic groups (26).

Percent blood alcohol content positivity-Two studies presented percent alcohol positive information on suicide fatalities using national data from the National Violent Death Reporting System (29, 30).

Native American subgroups: One study specifically examined Native American/Alaska Native race/ethnicity and found that individuals in this group had a higher percentage of alcohol positivity than any other racial/ethnic group (45.5\% vs. $22.9 \%-39.2 \%)(30)$.

Black and Hispanic subgroups: Both studies indicated that Hispanics had a higher and blacks had a lower percent alcohol positivity than whites did $(12,26)$.

Asian subgroups: Studies that have examined Asian race/ethnicity find that individuals in this group evidence low rates of alcohol positivity among suicides compared with other racial/ethnic groups (30).

\section{Intentional injury: homicide}

Overall alcohol-attributable injury rate-The same 2 studies examining overall rates of alcohol-attributable suicide in California reported on alcohol-attributable homicide (12, 26) (Table 4).

Native American subgroups: When Asians were disaggregated from "other" races/ ethnicities, the "other" racial/ethnic group had a higher rate of alcohol-attributable homicide (46.3 per 100,000) compared with Hispanics, whites, and Asians (26).

Black subgroups: Both studies indicated that blacks had the highest rate of alcoholattributable homicide of those racial/ethnic groups compared $(12,26)$.

Hispanic subgroups: Hispanics had a higher rate of alcohol-attributable homicide compared with whites $(12,26)$ and Asians $(26)$ and a lower rate than that for blacks.

Asian subgroups: Studies that have examined Asian race/ethnicity found that, compared with other racial/ethnic groups, individuals in this group evidenced low rates of alcoholattributable homicide (26).

Percent blood alcohol content positivity-Goodman et al. (31) reported on the proportion of alcohol positivity among homicide victims, documenting the highest rates among Latino males, followed by blacks, and the lowest rate among white males compared with all other males.

\section{Other unintentional injury—drowning, poisoning, falls, and unspecified injury}

In Table 5, we review studies of unintentional injury other than that involving motor vehicle crashes. All studies recorded overall alcohol-attributable injury rate. 
Native American subgroups: No studies examined Native-American race/ethnicity as a single category; thus, we inferred findings based on the "other" category when disaggregated from Asian subgroups. Individuals in the "other" race/ethnicity category had the highest rate of alcohol-attributable falls, a rate of poisoning similar to that for whites, and a similar rate of drowning when compared with non-Hispanic ethnic groups (26).

Black and Hispanic subgroups: With regard to general injury morbidity (based on emergency department visits) $(32,33)$ and mortality $(34)$, nonwhites generally had a higher alcohol-attributable risk than whites did, although the non-white group at highest risk depended on the groups compared.

Asian subgroups: Stahre and Simon (26) documented that those of Asian race/ethnicity evidenced similar rates of alcohol-attributable drowning compared with non-Hispanic racial/ ethnic groups and had higher rates of alcohol-attributable falls compared with those for Hispanics.

\section{DISCUSSION}

Table 6 summarizes the evidence synthesized from this review. Two key findings are highlighted. First, in general, for those injured, Native Americans and Asians have rates of alcohol-attributable injury and percent blood alcohol content positivity that would be expected given their level of alcohol consumption documented in national surveys. Native Americans are at higher risk of many alcohol-involved injury deaths than are individuals of other racial/ethnic groups, including motor vehicle crash fatality (driver, child occupant, or pedestrian), suicide, and falls; conversely, Asians have the lowest rates of most alcoholattributable outcomes of any ethnic group measured.

Second, the rate of alcohol positivity and intoxication for Hispanic injury deaths is disproportionately high relative to the use of alcohol documented in national survey data, particularly for injury involving motor vehicle crash, suicide, and homicide. Black subgroups also evidence higher rates of alcohol positivity than we would have expected given national estimates of alcohol use for some outcomes, including alcohol positivity among drivers of fatally injured black children and homicide. Racial/ethnic differences in rates of blood alcohol content positivity differ considerably from rates of overall alcoholattributable injury because overall rates are likely driven by factors unrelated to alcohol consumption (e.g., the rate of alcohol-attributable homicide is highest among blacks, consistent with the overall high rate of homicide among blacks due likely to non-alcoholrelated factors such as concentrated disadvantage and segregation (35-37)).

Thus, we found that rates of blood alcohol content positivity are particularly illuminating in examining alcohol-related health disparities. The results of this literature review are concordant with a 1991 review of race/ethnicity and drunk driving (38), which reported that blacks and Hispanics were disproportionately more likely to be involved in drunk driving yet less likely to be lifetime drinkers and less likely to binge drink compared with whites. This disparity between rates of alcohol consumption and rates of alcohol-attributable injury 
indicates that the fatal consequences of excessive alcohol consumption are higher for blacks and Hispanics than for other non-Hispanic whites.

The high rates of several alcohol-attributable injuries experienced by Native Americans compared with other racial/ethnic minorities as well as non-Hispanic whites highlight the well-documented health disparities in this group. Compared with other racial/ethnic groups including other minority groups, Native Americans are more likely to die of sudden infant death syndrome (39, 40), hypothermia (41), and complications due to type 2 diabetes (42), among other outcomes, and evidence indicates that this disparity is growing over time (43). Native Americans in the United States have a long history of structural discrimination, which is hypothesized to lead ultimately to a cascade of health problems and disparities that remain among the most pressing public health issues of our time (44).

The high prevalence of alcohol consumption and alcohol use disorders among some Native American groups is well documented. In Table 1, we present data from the largest population-based survey of alcohol use and related problems ever known to have been conducted in the United States; as shown, Native Americans/Alaska Natives have a higher prevalence of every alcohol outcome analyzed compared with all other racial/ethnic groups. Evidence suggests that Native Americans are less likely than other racial/ethnic groups to use seat restraints and child car seats $(19,45,46)$ and that use of child restraints and seat belts is inversely related to alcohol consumption (47). Further, national data indicate that Native Americans have higher rates of major depression than other racial/ethnic groups (48), which may at least partially explain higher overall alcohol-attributable suicide rates. Overall, these data highlight the continued public health importance of reducing excessive alcohol use among this high-risk population. Taken together, these results indicate that intervention and prevention programs to reduce problematic alcohol consumption among Native American populations may result in a reduced incidence of many health outcomes, including many injuries.

Blacks and Hispanics evidenced more fatal consequences of alcohol consumption for some injury outcomes than non-Hispanic whites did despite a lower population prevalence of alcohol use. Blacks and Hispanics had higher rates of alcohol positivity among those fatally injured in motor vehicle crashes as drivers, child occupants, or pedestrians and from suicide, homicide, and other unintentional injuries, especially alcohol poisoning (although we importantly note that not all studies were consistent regarding these findings $(24,26)$, suggesting more research is needed before a firm consensus can be formed). These results coincide with the broader injury literature showing that racial/ethnic minorities are more likely to die in a motor vehicle crash than non-Hispanic whites are (49). Further, these results are consistent with other health outcomes; for example, rates of alcohol-attributable cancers such as those of the esophagus and larynx are higher among non-Hispanic black men compared with non-Hispanic white men $(11,12)$. As shown in Table 1, populationbased estimates indicate that blacks, and especially Hispanics, are less likely than nonHispanic whites to consume alcohol, binge drink, and evidence alcohol use disorders, yet these groups are not only more likely to die from some alcohol-attributable injury outcomes, but, regarding injury deaths, individuals in these groups are also often more likely to be alcohol positive. 


\section{Differential underreporting of alcohol consumption by black and Hispanic subgroups}

One possible explanation for these results is that national surveys, which collect information on self-reported alcohol consumption, underestimate the true prevalence of consumption among black and Hispanic subgroups. This possibility would explain the results by suggesting that actual patterns of alcohol consumption for blacks and Hispanics are higher than those for whites, leading to a higher prevalence of alcohol-attributable injury. Limited data are available at the national level to validate self-reports of alcohol consumption or to evaluate the extent to which some racial/ethnic groups differentially underreport consumption. However, several factors strongly associated with lower alcohol consumption are more prevalent among black and Hispanic groups, most notably religiosity (50-52). This finding suggests that the lower prevalence of alcohol consumption among black and Hispanic groups compared with non-Hispanic whites, as reported by national surveys, is valid.

\section{Lower prevalence of health-promoting behaviors}

Some researchers have posited that the disparity in outcome for motor vehicle crash derives from a lower use of child car seats and seat belts $(19,45,46,53)$. For child-occupant deaths, blacks and Hispanics are more likely to have children in the car than non-Hispanic whites are, creating a higher exposure opportunity (49). However, for fatally injured children, the odds of having an alcohol-positive driver versus an alcohol-negative driver at the time of the death is equal across racial/ethnic groups (including black, Hispanic, Native American, Asian, and white), suggesting that, conditional on death, racial/ethnic minorities are not more likely to drive with a child while under the influence of alcohol (19). Further, the consistency of this finding across injury outcome suggests that exposure opportunity and restraint use do not entirely explain these results.

\section{Differential drinking patterns}

Others have suggested that perhaps blacks and Hispanics have a lower drinking frequency than whites do but that they drink more heavily per drinking occasion or consume beverages higher in alcohol content. If this pathway were operative, it would explain a higher risk of injury; evidence suggests that individuals who engage in heavy-volume occasional drinking are at a higher risk of injury outcomes (e.g., falls $(54,55)$, motor vehicle crash $(56)$, and suicide (57)) compared with individuals who engage in more frequent low-volume drinking.

Some specific problems associated with alcohol have been shown to be more common among racial/ethnic minorities who drink compared with non-Hispanic whites who drink, such as interpersonal and occupational problems and trouble with law enforcement $(14,58)$, although these factors could be linked to racial/ethnic discrimination. Evidence from the National Alcohol Survey indicated that blacks and Hispanics experience significantly higher rates of alcohol problems than non-Hispanic whites do, but only among those consuming very low levels of alcohol, suggesting that social context is an important aspect of the development of problem alcohol use (59). National data (e.g., Table 1) indicate that blacks and Hispanics are less likely to engage in any binge drinking as well as frequent binge drinking compared with non-Hispanic whites, although available data indicate substantial heterogeneity within racial/ethnic subgroups (60-62) that should be investigated more 
systematically as an explanation for these findings. Further, there is evidence that blacks and Hispanics experience a later age at onset of dependence but a longer persistence compared with non-Hispanic whites (13); in fact, some cross-sectional evidence exists of an age crossover in the epidemiology of alcohol use (15), whereby blacks and Hispanics in older age groups have higher rates of drinking than do non-Hispanic whites in the same age group.

\section{Neighborhood factors}

The disproportionate risk of alcohol-attributable homicide for non-Hispanic blacks and Hispanics, relative to non-Hispanic whites, may be partly related to a racial/ethnic difference in overall risk of homicide as well as to neighborhood factors. Independent of alcohol use, blacks and Hispanics are at higher risk of being victims and perpetrators of homicide (35), which may in itself partly explain the higher rate of alcohol-attributable homicide among these groups. Beyond this overall difference, however, blacks and Hispanics are more likely to reside in neighborhoods with higher concentrations of alcohol outlets and alcohol advertising $(63,64)$. Such outlets and ads are particularly directed at the sale of highalcohol-content beverages, which may lead to faster inebriation and contribute to the escalation of fights into fatal outcomes. In fact, area concentration of outlets and advertising has been repeatedly linked with a higher rate of homicide and nonfatal assault (65-67). Hence, the patterns of street and bar consumption of alcohol associated with concentration of such outlets may make low-income blacks and Hispanics particularly vulnerable to alcohol-attributable homicides.

Neighborhood factors may also explain disparities in alcohol poisoning. The unintentional drug overdose literature has shown that income inequality of the neighborhood is associated with rate of drug overdose (including overdose in which alcohol was detected on autopsy) (68) and that neighborhood disorganization and disorder at least partially mediate this relation (69). Given that alcohol poisoning is associated with unintentional drug overdose and that blacks as well as Hispanics, compared with non-Hispanic whites, have higher rates of alcohol poisoning, neighborhood and other contextual factors may at least partially explain this association. More generally, disadvantaged neighborhoods may have less access to and worse-quality health care resources in the event of an unintentional or intentional injury. Taken together, further examination of the context in which racial/ethnic minorities live and work as potential risk factors for alcohol-attributable injury is warranted.

\section{Unreliable racial/ethnic data}

Methodological issues may explain part of this discrepancy, but they are unlikely to explain all of it. Substantial evidence indicates differential misclassification and incomplete record keeping of racial/ethnic status for injury data. For example, data on the race/ethnicity of injured persons for the FARS record are typically drawn from the National Center for Health Statistics Multiple Cause of Death file. FARS and National Center for Health Statistics records are then matched to provide estimates of racial/ethnic differences in motor vehicle crash in which alcohol was involved; however, linkage rates between FARS and the Multiple Cause of Death file are lower for Hispanics compared with non-Hispanic whites (70), and 17 states report Hispanic ethnicity in less than $79 \%$ of crash fatalities (70). Further, states vary in the extent to which Hispanic ethnicities are included on death certificates (70), and 
Hispanic ethnicity is often unrecorded or incorrectly recorded on death certificates (71-73). The reliability of race/ethnicity recorded on death certificates in the United States ranges from a kappa of $98 \%$ for whites and blacks to only $57 \%$ for Native Americans and less than $50 \%$ for some Hispanic ethnicities (74). In addition, blood alcohol content is recorded in the FARS data for a majority of drivers involved in fatality-resulting motor vehicle crash, but differences are documented by race/ethnicity (by racial/ethnic group, the percentage tested ranges from $69 \%$ among blacks to $79 \%$ among Asians (18)).

\section{Subgroup variation}

Categorization of individuals according to subjective and dynamic concepts such as "race" and "ethnicity" is, while powerfully predictive of health, problematic (75). Definition of these terms depends on the context, changes over time, and has little meaning beyond predicting social circumstances (76). Even when studies included in the present review attempted to disaggregate rates beyond white versus nonwhite, substantial misclassification is likely present. Further, most studies combine all those who report Hispanic ethnicity into a single category, which may obscure important subgroup variation (20); previous studies have documented substantial variation in patterns of alcohol use within ethnic subgroups $(13,60$ $62,77)$. Discrete categories also create false dichotomies between categories such as black and Hispanic (i.e., in reality, these groups overlap substantially).

In general, however, we acknowledge the inherent limitations in using administrative classes based on ambiguous concepts such as race and ethnicity, but we point to the importance of continuing to study outcomes across racial/ethnic groups, despite these problems, to identify and ultimately rectify inequities. These misclassification errors would explain the higher alcohol-attributable death rate only if those Hispanics who were incorrectly classified were less likely than correctly classified Hispanics to experience an alcohol-attributable death. While some differential misclassification of this nature is plausible, it is unlikely to account for all of the differences we found. More data on the association between alcohol consumption and misclassification would be useful to tease apart these associations. The alcohol injury literature would be served by greater attention to ethnic subgroups rather than race classifications, as has been the direction in alcohol epidemiologic literature more broadly.

\section{Discrimination and prejudice}

Additionally, there may be racial bias in the assessment of alcohol positivity among injury victims, in police involvement, or in bystander aid (leading to more fatal consequences of alcohol-involved injury). Crosby et al. (30) documented that blacks and Hispanics classified as suicides are more likely than non-Hispanic whites to be tested for drugs and alcohol. In fact, blacks are most likely to be tested but are least likely to be found positive. Consistent with this, Voas et al. (20) found that drivers of black and Hispanic children fatally injured in a motor vehicle crash are more likely to be tested for drugs and alcohol compared with drivers of non-Hispanic white children. Further, blacks and Hispanics may face greater scrutiny for alcohol use when police or law enforcement become involved in a situation in which injury has occurred. Finally, research in experimental psychology has demonstrated that bystanders are less willing to intervene to aid racial/ethnic minorities (78), which may 
lead to more fatal consequences of an injury if medical assistance is delayed. Additional research into this issue is necessary to gauge how much this bias accounts for the discrepancy between alcohol consumption and injury outcomes, an important future step in this research area.

\section{Foci for future research}

Given that the FARS database has included information on race/ethnicity for over a decade, more research using this database to explore racial/ethnic correlates of driver-related, roadrelated, and vehicle-related injury is accessible, publicly available, and needed to fully understand the patterns presented here. Future research should focus on effect-measure modifiers of the relation between race/ethnicity and injury outcomes to elucidate the pathways through which these effects arise. For example, Abdel-Aty and Abdelwahab (28) found that nonwhites had higher rates of alcohol-attributable injury compared with whites only after age 55 years, suggesting important age-related variation in the relation between race/ethnicity and injury.

These results are consistent with those from major epidemiologic studies of alcohol comparing blacks and whites, which suggest that whites have higher rates of alcohol and tobacco use at younger ages, but, at older ages, no differences between blacks and whites are observed or blacks have slightly higher rates than whites do (79). Among Hispanics, more attention to background, immigration status, and bicultural identity is necessary to fully understand the troubling increases in alcohol-attributable injury risk. As shown in this review, and consistent with the alcohol epidemiologic literature $(60,80,81)$, rates of alcohol consumption and alcohol-attributable injury are lower among more recent immigrants to the United States compared with native-born persons or immigrants living for a longer time in the United States. Further, the likelihood of alcohol involvement varies by injury severity (82), and we did not identify any studies that examined racial/ethnic differences in injury severity (other than nonfatal vs. fatal, whereby results were largely consistent). Future research incorporating race/ethnicity and injury severity would provide much needed nuance to this literature.

Additionally, the extent to which these results are driven by socioeconomic differences between racial/ethnic groups is not firmly established. Voas et al. (18) and Braver et al. (21) documented that racial/ethnic differences are substantially attenuated if not completely explained when indicators of socioeconomic position are controlled, yet reliable socioeconomic data are not routinely incorporated into studies of racial/ethnic differences in injury. Finally, the validity of the results presented here is largely dependent on the validity of ARDI estimates, which calculate the contribution of alcohol to major causes of death (83). The ARDI is based on empirical studies, few of which incorporated distinctions between ethnic groups and all of which may have internal biases that affect the results of the ARDI and thus this review.

In conclusion, this review indicates that some patterns of racial/ethnic differences in alcoholattributable injury, particularly for blacks and Hispanics, cannot be easily explained by racial/ethnic differences in patterns of alcohol consumption. This is a conspicuous gap in the literature for which more research is needed. The present review also indicates that Native 
Americans remain at high risk of many alcohol-attributable injury outcomes, especially motor vehicle crash involving pedestrian, occupant, and driver fatalities. While blacks and Hispanics currently evidence lower rates of binge drinking compared with non-Hispanic whites, time-trend analysis indicates increases in binge drinking since 1979 among black and Hispanic groups, especially women, suggesting that increased attention to the consequences of drinking by racial/ethnic minorities is urgently needed. Further, data from the Centers for Disease Control and Prevention suggest that suicide rates among black youth have been increasing since 1980 (84), suggesting the need for an increase in public health resources. Finally, more detailed data on racial/ethnic differences in injury outcomes is needed to develop and empirically test theories regarding the etiology of injury differences across racial/ethnic groups. Such theories may promote the development of public health prevention and intervention efforts and also more broadly inform study of the social epidemiology of health.

\title{
Acknowledgments
}

This research was supported in part by a grant (K01 DA030449-01) from the National Institute on Drug Abuse to M. C.

\section{Abbreviations}

\author{
ARDI Alcohol-Related Disease Impact \\ FARS Fatality Analysis Reporting System
}

\section{References}

1. Rivara FP, Garrison MM, Ebel B, et al. Mortality attributable to harmful drinking in the United States, 2000. J Stud Alcohol. 2004; 65(4):530-536. [PubMed: 15376828]

2. Rehm J, Baliunas D, Borges GL, et al. The relation between different dimensions of alcohol consumption and burden of disease: an overview. Addiction. 2010; 105(5):817-843. [PubMed: 20331573]

3. Rehm J, Mathers C, Popova S, et al. Global burden of disease and injury and economic cost attributable to alcohol use and alcohol-use disorders. Lancet. 2009; 373(9682):2223-2233. [PubMed: 19560604]

4. Stenbacka M, Leifman A, Dalal K, et al. Early predictors of injury mortality among Swedish conscripts: a 35-year cohort study. Accid Anal Prev. 2011; 43(1):228-234. [PubMed: 21094318]

5. Britton A, McPherson K. Mortality in England and Wales attributable to current alcohol consumption. J Epidemiol Community Health. 2001; 55(6):383-388. [PubMed: 11350993]

6. National Highway Traffic Safety Administration USDoT. Total fatalities in drunk-driving crashes, 1982-2009. Washington, DC: US Department of Transportation; 2010. (http://wwwnrd.nhtsa.dot.gov/Pubs/811363.pdf) [Accessed June 17, 2011]

7. Chandran A, Hyder AA, Peek-Asa C. The global burden of unintentional injuries and an agenda for progress. Epidemiol Rev. 2010; 32:110-120. [PubMed: 20570956]

8. Barss, P., Smith, G., Baker, S., et al. Injury Prevention: An International Perspective. Epidemiology, Surveillance, and Policy. New York, NY: Oxford University Press; 1998.

9. Alcohol-attributable deaths and years of potential life lost-United States, 2001. MMWR Morb Mortal Wkly Rep. 2004; 53(37):866-870. [PubMed: 15385917]

10. Hasin DS, Stinson FS, Ogburn E, et al. Prevalence, correlates, disability, and comorbidity of DSMIV alcohol abuse and dependence in the United States: results from the National Epidemiologic 
Survey on Alcohol and Related Conditions. Arch Gen Psychiatry. 2007; 64(7):830-842. [PubMed: 17606817]

11. Polednak AP. Secular trend in U.S. black-white disparities in selected alcohol-related cancer incidence rates. Alcohol Alcohol. 2007; 42(2):125-130. [PubMed: 17255152]

12. Sutocky JW, Shultz JM, Kizer KW. Alcohol-related mortality in California, 1980 to 1989. Am J Public Health. 1993; 83(6):817-823. [PubMed: 8498618]

13. Chartier K, Caetano R. Ethnicity and health disparities in alcohol research. Alcohol Res Health. 2010; 33(1-2):152-160. [PubMed: 21209793]

14. Caetano R. Prevalence, incidence and stability of drinking problems among whites, blacks and Hispanics: 1984-1992. J Stud Alcohol. 1997; 58(6):565-572. [PubMed: 9391915]

15. Watt TT. The race/ethnic age crossover effect in drug use and heavy drinking. J Ethn Subst Abuse. 2008; 7(1):93-114. [PubMed: 19842303]

16. Fullilove MT. Comment: abandoning "race" as a variable in public health research—an idea whose time has come. Am J Public Health. 1998; 88(9):1297-1298. [PubMed: 9736864]

17. Centers for Disease Control and Prevention. Alcohol-Related Disease Impact (ARDI) software. Atlanta, GA: Centers for Disease Control and Prevention; 2011. (http://www.cdc.gov/alcohol) [Accessed June 17, 2011]

18. Voas RB, Fisher DA, Tippetts AS. Children in fatal crashes: driver blood alcohol concentration and demographics of child passengers and their drivers. Addiction. 2002; 97(11):1439-1448. [PubMed: 12410784]

19. Voas, RB., Fisher, DA., Tippetts, AS. Child endangerment: differences across racial and ethnic groups in the U.S. in driver alcohol use and restraint of child passengers. Alcohol, drugs and traffic safety-T 2000. Proceedings of the 15th International Conference on Alcohol, Drugs and Traffic Safety; Stockholm, Sweden. May 22-26, 2000; p. 125-131.

20. Voas, R., Tippetts, S., Fisher, D. Ethnicity and alcohol-related fatalities: 1990 to 1994. Washington, DC: National Highway Traffic Safety Administration; 2000. (DOT HS 809 068). (http:// www.nhtsa.gov/people/injury/alcohol/Archive/ethnicity/ethnicity.html) [Accessed June 17, 2011]

21. Braver ER. Race, Hispanic origin, and socioeconomic status in relation to motor vehicle occupant death rates and risk factors among adults. Accid Anal Prev. 2003; 35(3):295-309. [PubMed: 12643947]

22. Campos-Outcalt D, Prybylski D, Watkins AJ, et al. Motor-vehicle crash fatalities among American Indians and non-Indians in Arizona, 1979 through 1988. Am J Public Health. 1997; 87(2):282285. [PubMed: 9103112]

23. Campos-Outcalt D, Bay C, Dellapenna A, et al. Pedestrian fatalities by race/ethnicity in Arizona, 1990-1996. Am J Prev Med. 2002; 23(2):129-135. [PubMed: 12121801]

24. Campos-Outcalt D, Bay C, Dellapena A, et al. Motor vehicle crash fatalities by race/ethnicity in Arizona, 1990-96. Inj Prev. 2003; 9(3):251-256. [PubMed: 12966015]

25. Harper JS, Marine WM, Garrett CJ, et al. Motor vehicle crash fatalities: a comparison of Hispanic and non-Hispanic motorists in Colorado. Ann Emerg Med. 2000; 36(6):589-596. [PubMed: 11097699]

26. Stahre M, Simon M. Alcohol related deaths and hospitalizations by race, gender, and age in California. Open Epidemiol J. 2010; 3:3-15.

27. Popkin CL, Council FM. A comparison of alcohol-related driving behavior of white and nonwhite North Carolina drivers. Accid Anal Prev. 1993; 25(4):355-364. [PubMed: 8357449]

28. Abdel-Aty MA, Abdelwahab HT. Exploring the relationship between alcohol and the driver characteristics in motor vehicle accidents. Accid Anal Prev. 2000; 32(4):473-482. [PubMed: 10868750]

29. Karch DL, Barker L, Strine TW. Race/ethnicity, substance abuse, and mental illness among suicide victims in 13 US states: 2004 data from the National Violent Death Reporting System. Inj Prev. 2006; 12(suppl 2):ii22-ii27. [PubMed: 17170166]

30. Alcohol and suicide among racial/ethnic populations-17 states, 2005-2006. MMWR Morb Mortal Wkly Rep. 2009; 58(23):637-641. [PubMed: 19543198]

31. Goodman RA, Mercy JA, Loya F, et al. Alcohol use and interpersonal violence: alcohol detected in homicide victims. Am J Public Health. 1986; 76(2):144-149. [PubMed: 3946695] 
32. Borges G, Cherpitel C, Mittleman M. Risk of injury after alcohol consumption: a case-crossover study in the emergency department. Soc Sci Med. 2004; 58(6):1191-1200. [PubMed: 14723913]

33. McDonald AJ III, Wang N, Camargo CA Jr. US emergency department visits for alcohol-related diseases and injuries between 1992 and 2000. Arch Intern Med. 2004; 164(5):531-537. [PubMed: 15006830]

34. Stinson FS, DeBakey SF. Alcohol-related mortality in the United States, 1979-1988. Br J Addict. 1992; 87(5):777-783. [PubMed: 1591529]

35. Logan JE, Smith SG, Stevens MR. Homicides-United States, 1999-2007. Centers for Disease Control and Prevention (CDC). MMWR Surveill Summ. 2011; 60(suppl):67-70.

36. Eitle D. Dimensions of racial segregation, hypersegregation, and Black homicide rates. J Crim Just. 2009; 37(1):28-36.

37. Feldmeyer B. The effects of racial/ethnic segregation on Latino and Black homicide. Sociol Q. 2010; 51(4):600-623. [PubMed: 20939127]

38. Ross HL, Howard JM, Ganikos ML, et al. Drunk driving among American blacks and Hispanics. Accid Anal Prev. 1991; 23(1):1-11. [PubMed: 2021398]

39. Iyasu S, Randall LL, Welty TK, et al. Risk factors for sudden infant death syndrome among northern plains Indians. JAMA. 2002; 288(21):2717-2723. [PubMed: 12460095]

40. Kinney HC, Thach BT. The sudden infant death syndrome. N Engl J Med. 2009; 361(8):795-805. [PubMed: 19692691]

41. Gallaher MM, Fleming DW, Berger LR, et al. Pedestrian and hypothermia deaths among Native Americans in New Mexico. Between bar and home. JAMA. 1992; 267(10):1345-1348. [PubMed: 1740855]

42. Gregg EW, Gu Q, Cheng YJ, et al. Mortality trends in men and women with diabetes, 1971 to 2000. Ann Intern Med. 2007; 147(3):149-155. [PubMed: 17576993]

43. Adler NE, Rehkopf DH. U.S. disparities in health: descriptions, causes, and mechanisms. Annu Rev Public Health. 2008; 29:235-252. [PubMed: 18031225]

44. Young, TK. The Health of Native Americans: Towards a Biocultural Epidemiology. New York, NY: Oxford University Press; 1994.

45. Niemcryk SJ, Kaufmann CR, Brawley M, et al. Motor vehicle crashes, restraint use, and severity of injury in children in Nevada. Am J Prev Med. 1997; 13(2):109-114. [PubMed: 9088447]

46. Mayrose J, Jehle DV. An analysis of race and demographic factors among motor vehicle fatalities. J Trauma. 2002; 52(4):752-755. [PubMed: 11956395]

47. Gross EA, Axberg A, Mathieson K. Predictors of seatbelt use in American Indian motor vehicle crash trauma victims on and off the reservation. Accid Anal Prev. 2007; 39(5):1001-1005. [PubMed: 17854575]

48. Hasin DS, Goodwin RD, Stinson FS, et al. Epidemiology of major depressive disorder: results from the National Epidemiologic Survey on Alcoholism and Related Conditions. Arch Gen Psychiatry. 2005; 62(10):1097-1106. [PubMed: 16203955]

49. Baker SP, Braver ER, Chen LH, et al. Motor vehicle occupant deaths among Hispanic and black children and teenagers. Arch Pediatr Adolesc Med. 1998; 152(12):1209-1212. [PubMed: 9856431]

50. Gibson LM, Hendricks CS. Integrative review of spirituality in African American breast cancer survivors. ABNF J. 2006; 17(2):67-72. [PubMed: 18402346]

51. Giger JN, Appel SJ, Davidhizar R, et al. Church and spirituality in the lives of the African American community. J Transcult Nurs. 2008; 19(4):375-383. [PubMed: 18650398]

52. Taylor RJ, Chatters LM, Jayakody RT, et al. Black and white differences in religious participation: a multi-sample comparison. J Sci Study Relig. 1996; 35:403-410.

53. Matteucci RM, Holbrook TL, Hoyt DB, et al. Trauma among Hispanic children: a populationbased study in a regionalized system of trauma care. Am J Public Health. 1995; 85(7):1005-1008. [PubMed: 7604898]

54. Honkanen R, Ertama L, Kuosmanen P, et al. The role of alcohol in accidental falls. J Stud Alcohol. 1983; 44(2):231-245. [PubMed: 6645509] 
55. Gmel G, Bissery A, Gammeter R, et al. Alcohol-attributable injuries in admissions to a Swiss emergency room - an analysis of the link between volume of drinking, drinking patterns, and preattendance drinking. Alcohol Clin Exp Res. 2006; 30(3):501-509. [PubMed: 16499491]

56. Naimi TS, Brewer RD, Mokdad A, et al. Binge drinking among US adults. JAMA. 2003; 289(1): 70-75. [PubMed: 12503979]

57. Borges G, Rosovsky H. Suicide attempts and alcohol consumption in an emergency room sample. J Stud Alcohol. 1996; 57(5):543-548. [PubMed: 8858552]

58. Caetano R. The association between severity of DSM-III-R alcohol dependence and medical and social consequences. Addiction. 1993; 88(5):631-642. [PubMed: 8518713]

59. Mulia N, Ye Y, Greenfield TK, et al. Disparities in alcohol-related problems among white, black, and Hispanic Americans. Alcohol Clin Exp Res. 2009; 33(4):654-662. [PubMed: 19183131]

60. Caetano R, Ramisetty-Mikler S, Wallisch LS, et al. Acculturation, drinking, and alcohol abuse and dependence among Hispanics in the Texas-Mexico border. Alcohol Clin Exp Res. 2008; 32(2): 314-321. [PubMed: 18162071]

61. Caetano R, Clark CL, Tam T. Alcohol consumption among racial/ethnic minorities: theory and research. Alcohol Health Res World. 1998; 22(4):233-241. [PubMed: 15706749]

62. Caetano R, McGrath C. Driving under the influence (DUI) among U.S. ethnic groups. Accid Anal Prev. 2005; 37(2):217-224. [PubMed: 15667807]

63. Kwate NO. Take one down, pass it around, 98 alcohol ads on the wall: outdoor advertising in New York City's black neighbourhoods. Int J Epidemiol. 2007; 36(5):988-990. [PubMed: 17591640]

64. Kwate NO, Meyer IH. Association between residential exposure to outdoor alcohol advertising and problem drinking among African American women in New York City. Am J Public Health. 2009; 99(2):228-230. [PubMed: 19059857]

65. Gruenewald PJ, Freisthler B, Remer L, et al. Ecological associations of alcohol outlets with underage and young adult injuries. Alcohol Clin Exp Res. 2010; 34(3):519-527. [PubMed: 20028361]

66. Gruenewald PJ, Remer L. Changes in outlet densities affect violence rates. Alcohol Clin Exp Res. 2006; 30(7):1184-1193. [PubMed: 16792566]

67. Jones-Webb R, McKee P, Hannan P, et al. Alcohol and malt liquor availability and promotion and homicide in inner cities. Subst Use Misuse. 2008; 43(2):159-177. [PubMed: 18205086]

68. Galea S, Ahern J, Vlahov D, et al. Income distribution and risk of fatal drug overdose in New York City neighborhoods. Drug Alcohol Depend. 2003; 70(2):139-148. [PubMed: 12732407]

69. Nandi A, Galea S, Ahern J, et al. What explains the association between neighborhood-level income inequality and the risk of fatal overdose in New York City? Soc Sci Med. 2006; 63(3):662674. [PubMed: 16597478]

70. Briggs NC, Levine RS, Haliburton WP, et al. The Fatality Analysis Reporting System as a tool for investigating racial and ethnic determinants of motor vehicle crash fatalities. Accid Anal Prev. 2005; 37(4):641-649. [PubMed: 15949455]

71. Arias E, Schauman WS, Eschbach K, et al. The validity of race and Hispanic origin reporting on death certificates in the United States. Vital Health Stat 2. 2008; (148):1-23.

72. Hahn RA, Wetterhall SF, Gay GA, et al. The recording of demographic information on death certificates: a national survey of funeral directors. Public Health Rep. 2002; 117(1):37-43. [PubMed: 12297680]

73. Polednak AP. Estimating mortality in the Hispanic population of Connecticut, 1990 to 1991. Am J Public Health. 1995; 85(7):998-1001. [PubMed: 7604930]

74. Rosenberg HM, Maurer JD, Sorlie PD, et al. Quality of death rates by race and Hispanic origin: a summary of current research, 1999. Vital Health Stat 2. 1999; (128):1-13.

75. Bhopal R, Donaldson L. White, European, Western, Caucasian, or what? Inappropriate labeling in research on race, ethnicity, and health. Am J Public Health. 1998; 88(9):1303-1307. [PubMed: 9736867]

76. Dressler WW, Oths KS, Gravlee CC. Race and ethnicity in public health research: models to explain health disparities. Annu Rev Anthropol. 2005; 34:231-252. 
77. Caetano R. Ethnicity and drinking in northern California: a comparison among whites, blacks and Hispanics. Alcohol Alcohol. 1984; 19(1):31-44. [PubMed: 6497950]

78. Gaertner SL, Dovidio JF. The subtlety of White racism, arousal, and helping behavior. J Pers Soc Psychol. 1977; 35(10):691-707.

79. Geronimus AT, Neidert LJ, Bound J. Age patterns of smoking in US black and white women of childbearing age. Am J Public Health. 1993; 83(9):1258-1264. [PubMed: 8363001]

80. Alegria M, Canino G, Stinson FS, et al. Nativity and DSM-IV psychiatric disorders among Puerto Ricans, Cuban Americans, and non-Latino Whites in the United States: results from the National Epidemiologic Survey on Alcohol and Related Conditions. J Clin Psychiatry. 2006; 67(1):56-65.

81. Grant BF, Stinson FS, Hasin DS, et al. Immigration and lifetime prevalence of DSM-IV psychiatric disorders among Mexican Americans and non-Hispanic whites in the United States: results from the National Epidemiologic Survey on Alcohol and Related Conditions. Arch Gen Psychiatry. 2004; 61(12):1226-1233. [PubMed: 15583114]

82. Hingson R, Winter M. Epidemiology and consequences of drinking and driving. Alcohol Res Health. 2003; 27(1):63-78. [PubMed: 15301401]

83. Smith GS, Branas CC, Miller TR. Fatal nontraffic injuries involving alcohol: a metaanalysis. Ann Emerg Med. 1999; 33(6):659-668. [PubMed: 10339681]

84. Suicide among Black youth-United States 1980-1995. MMWR Surveill Summ. 2003; 47(10): 193-196.

85. Caetano R. Acculturation, drinking and social setting among U.S. Hispanics. Drug Alcohol Depend. 1987; 19(3):215-226. [PubMed: 3595446]

86. Yoon YH, Stinson FS, Yi HY, et al. Accidental alcohol poisoning mortality in the United States, 1996-1998. Alcohol Res Health. 2003; 27(1):110-118. [PubMed: 15301405] 


\section{Table 1}

Prevalence (\%) of Lifetime Alcohol Use, Binge Drinking, Frequent Binge Drinking, and DSM-IV Alcohol Abuse/Dependence by Race/Ethnicity in the United States: Results from the National Epidemiologic Survey on Alcohol and Related Conditions ${ }^{a}$

\begin{tabular}{|c|c|c|c|c|}
\hline & Ever Drink Alcohol & $\begin{array}{l}\text { Ever Binge Drink } \\
\text { ( } \leq 5 \text { Drinks for } \\
\text { Men, } \geq 4 \text { for } \\
\text { Women) }\end{array}$ & $\begin{array}{r}\text { Ever Frequently } \\
\text { Binge Drink (Once } \\
\text { per Week or More) }\end{array}$ & Lifetime Alcohol Abuse/Dependence \\
\hline Non-Hispanic white & 86.60 & 41.20 & 25.30 & 34.10 \\
\hline Non-Hispanic black & 75.30 & 24 & 15.70 & 20.60 \\
\hline $\begin{array}{l}\text { Non-Hispanic American } \\
\text { Indian/Alaska Native }\end{array}$ & 82.90 & 47.60 & 33.20 & 43 \\
\hline Non-Hispanic Asian & 60.90 & 17.20 & 9.20 & 11.60 \\
\hline Hispanic & 74.30 & 34.10 & 18.40 & 21 \\
\hline
\end{tabular}

Abbreviation: DSM-IV, Diagnostic and Statistical Manual of Mental Disorders, Fourth Edition.

${ }^{a}$ Analyzed by using publicly available data. Estimates of lifetime alcohol abuse/dependence were published previously by Hasin et al. (10). 


\section{Table 2}

ICD-9 and ICD-10 Codes Corresponding to Classifications of Injury Outcomes Used in the Present Review of Race/Ethnicity and Alcohol-attributable Injury in the United States

\begin{tabular}{lll}
\hline & ICD-9 Code(s) & ICD-10 Code(s) \\
\hline Motor vehicle crash & E800-807, E810-E829 & V01-V03.0, V03.9, V04(0.0, 0.1, 0.9), V05-V06, V09-V89.9 \\
Suicide & E950-E959 & X60-X64, X66-X84, X87.0 \\
Homicide & E960-E969 & X85-Y09, Y87.1 \\
Falls & E848, E880-E888 & W00-W19 \\
Fires & E890-E899 & X00-X09 \\
Drowning & W65-W74 & E910 \\
Poisoning & E860(0.0, 0.1) & X45, T51.0, T51.1, Y15 \\
\hline
\end{tabular}

Abbreviations: ICD-9, International Classification of Diseases, Ninth Revision; ICD-10, International Statistical Classification of Diseases and Related Health Problems, Tenth Revision. 


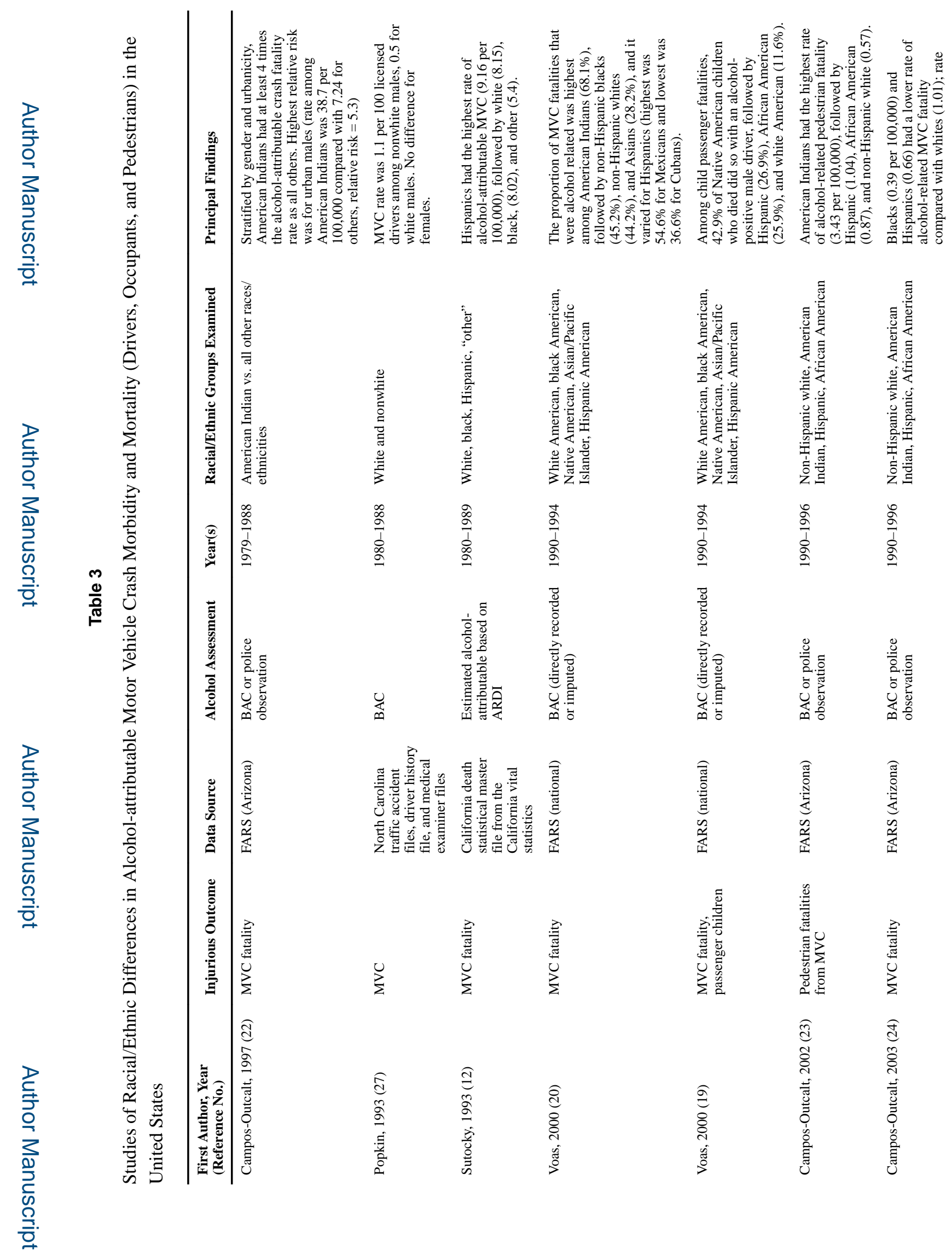


Keyes et al.

Page 21

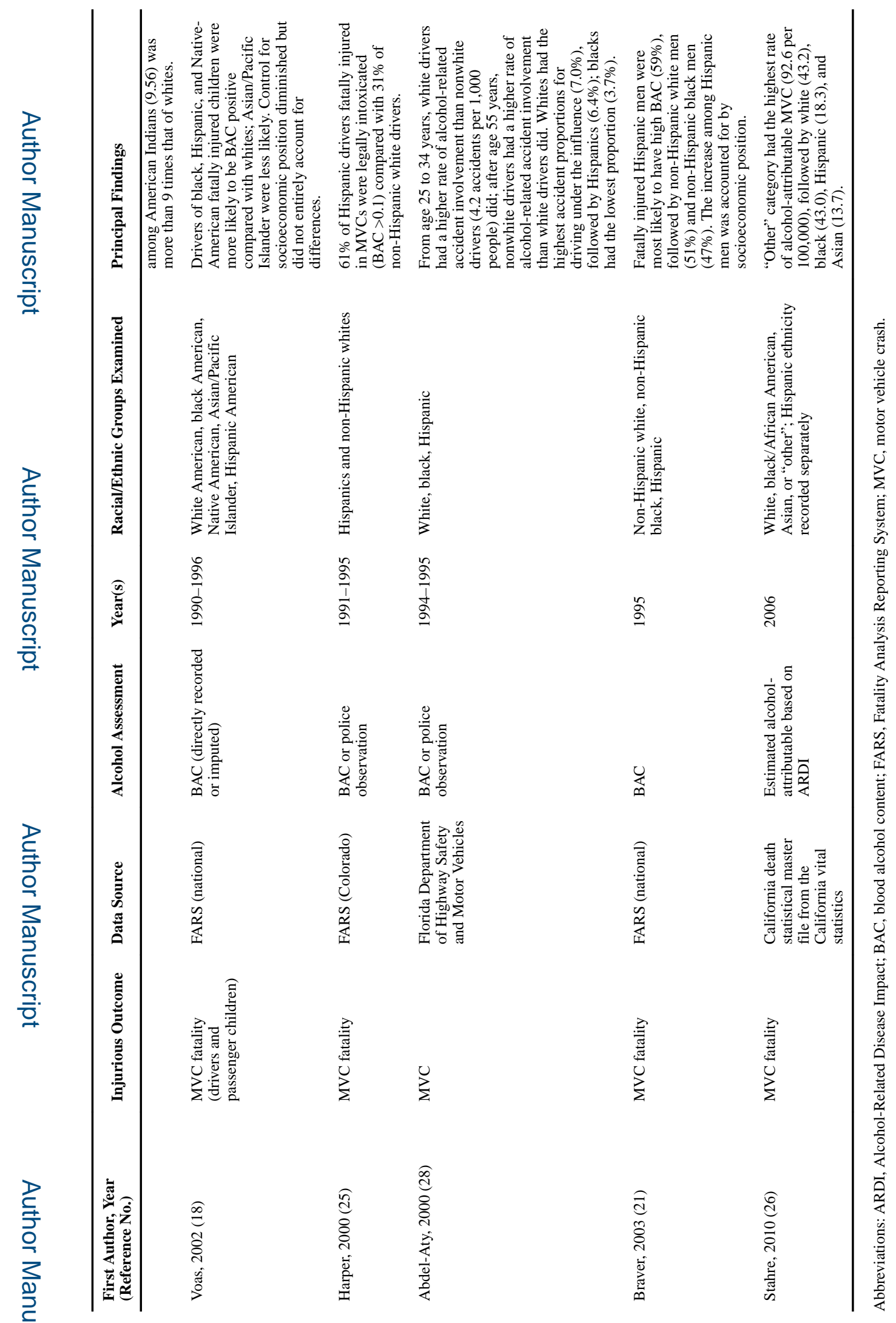

Alcohol Clin Exp Res. Author manuscript; available in PMC 2017 August 02. 


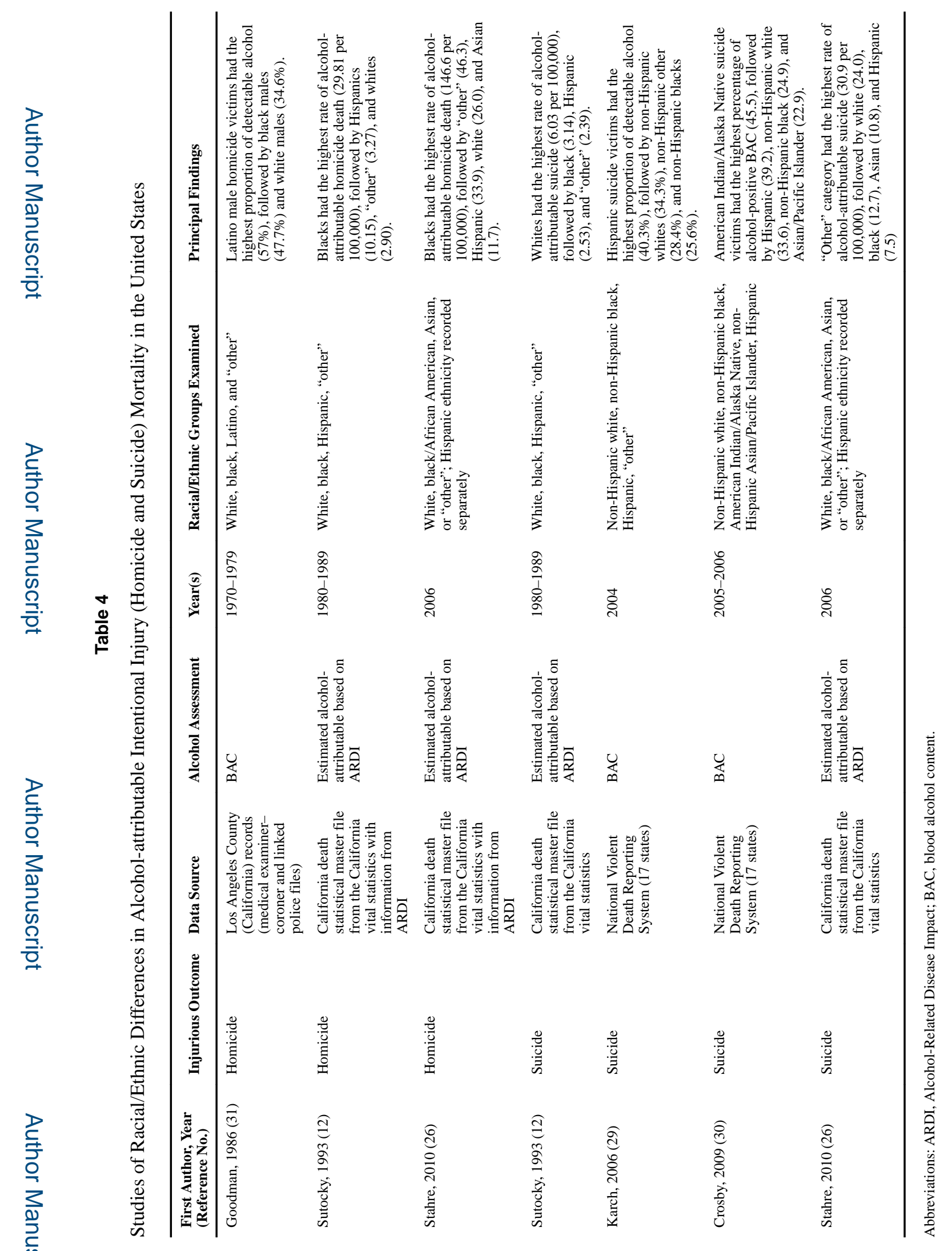

Alcohol Clin Exp Res. Author manuscript; available in PMC 2017 August 02. 


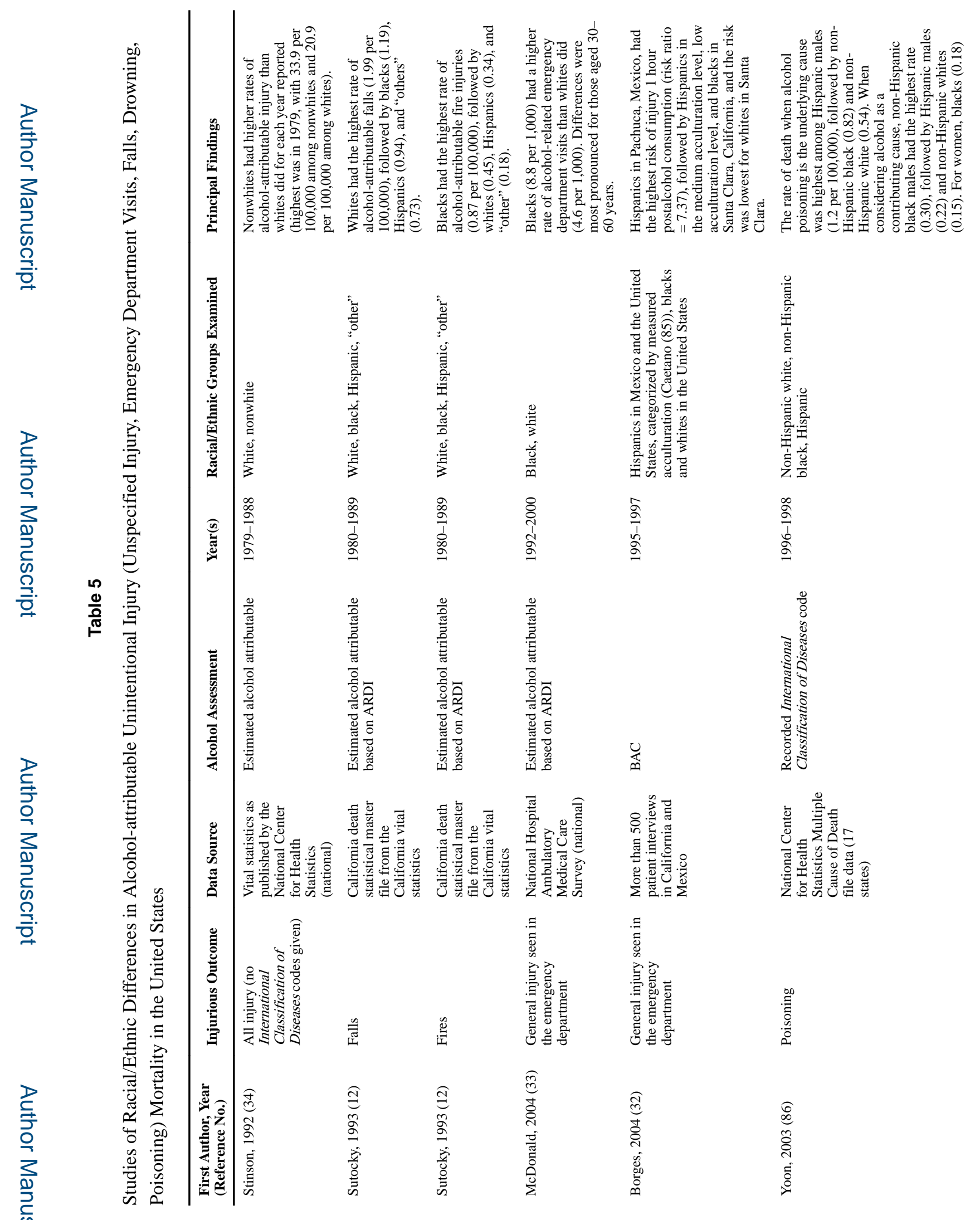


Keyes et al.

Page 24

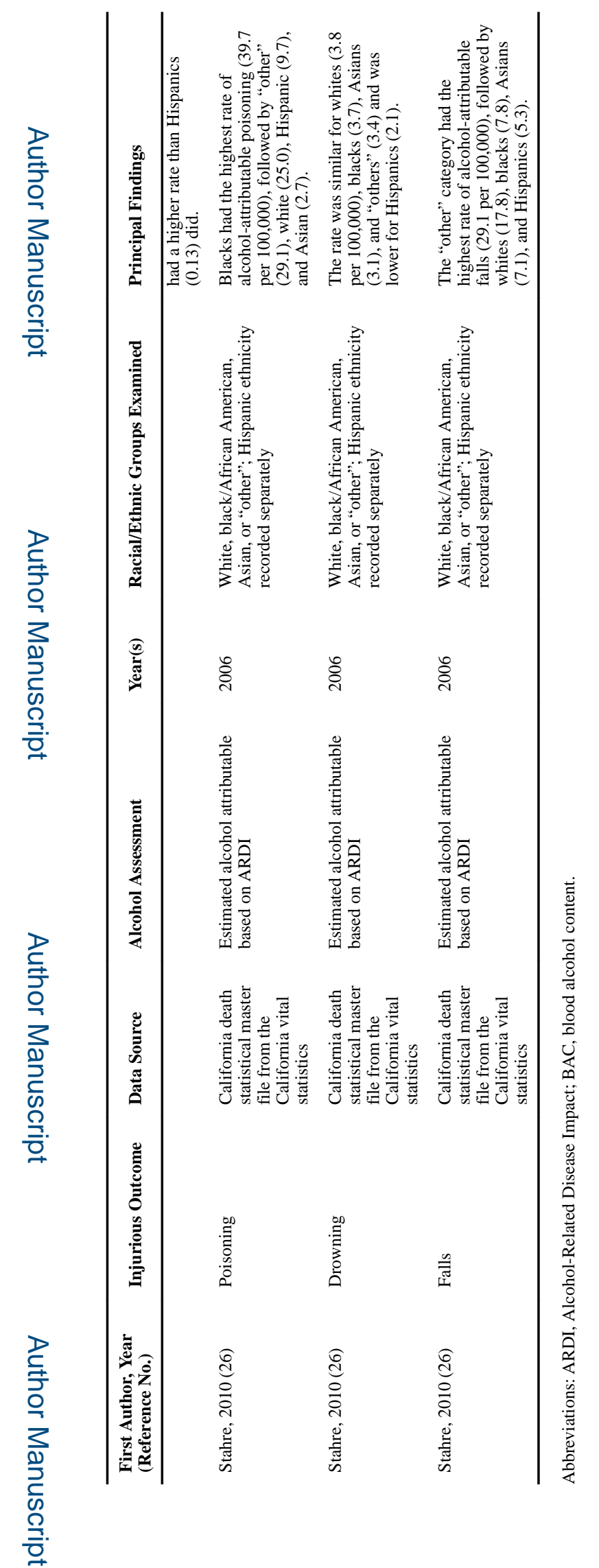

Alcohol Clin Exp Res. Author manuscript; available in PMC 2017 August 02. 


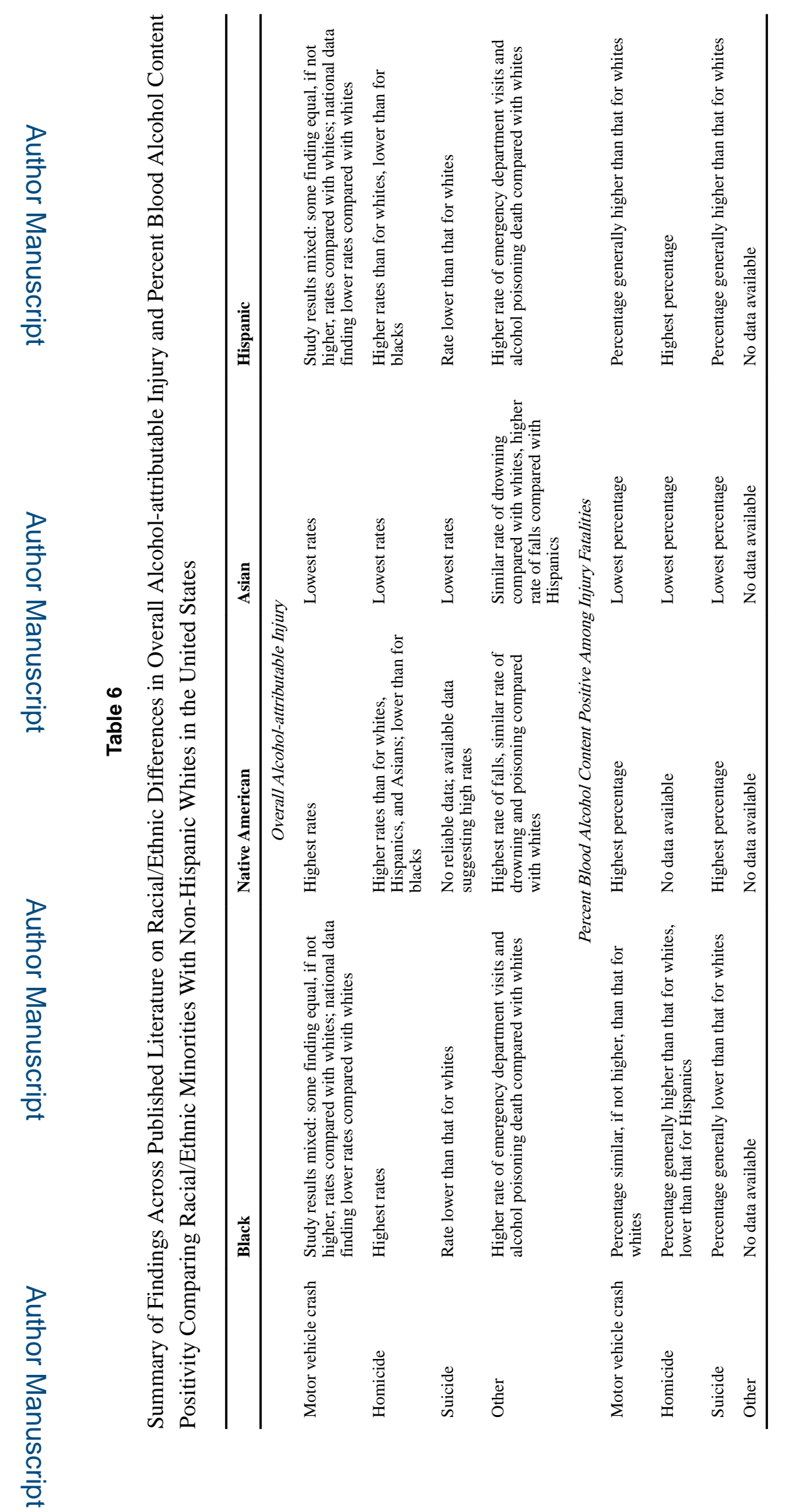

Alcohol Clin Exp Res. Author manuscript; available in PMC 2017 August 02. 